\title{
PROJETO ESCOLA EM TEMPO INTEGRAL NO MUNICIPIO DE JOÃO PESSOA-PB: CONTEXTOS E PRÁTICA
}

\author{
Ruttany de Souza Alves Ferreira* \\ Cibele Maria Lima Rodrigues** \\ Gilvaneide Ferreira de Oliveira***
}

\begin{abstract}
RESUMO
O presente artigo objetiva analisar o contexto de implantação do Projeto "Escola de Tempo Integral" em uma escola de ensino fundamental na cidade de João Pessoa-PB, assim como compreender como esta política é efetivada na prática em uma escola de ensino fundamental (anos iniciais) da rede municipal. Para coleta de dados foram realizadas entrevistas semiestruturadas e observações. Como principais resultados encontrou-se que o modelo adotado em João Pessoa está centrado na ampliação do tempo, na perspectiva do aluno em tempo integral. O Projeto em tela possui visíveis influências do Programa Mais Educação. Na prática, a extensão da carga horária está atrelada à proteção social. Também se organiza a partir do discurso das avaliações padronizadas ao reforçar o estudo dos conteúdos curriculares de português e matemática, visando elevar as médias nas referidas disciplinas. Além disso, a Secretaria possui um sistema próprio de avaliação que segue a mesma lógica - o chamado Programa Escola Nota 10. Os sujeitos que desempenham funções docentes, em especial as professoras e tutoras, são cobrados para que as crianças atinjam o desempenho necessário a fim de ganhar a premiação do Programa Escola Nota 10. Desse modo, o trabalho da instituição gira em torno das normas de tal Programa.

Palavras-chave: Política educacional. Ampliação da jornada escolar. Qualidade da educação.
\end{abstract}

\section{ABSTRACT \\ SCHOOL PROJECT IN COMPREHENSIVE TIME IN THE MUNICIPALITY OF JOÃO PESSOA-PB: CONTEXTS AND PRACTICE}

This article aims to analyze the context of the implementation of the Project "Integral School" in a primary school in the city of João Pessoa-PB, as well as to understand

\footnotetext{
Mestra em Educação, Culturas e Identidades pela Fundação Joaquim Nabuco e Universidade Federal Rural de Pernambuco (Fundaj/UFRPE). Coordenadora Pedagógica da Escola Carrossel Prisma. Técnica Pedagógica do Núcleo das Escolas Estaduais Cidadãs Integrais da Paraíba. E-mail: ruttanysouza@gmail.com.

** Pesquisadora da Fundação Joaquim Nabuco (Fundaj). Professora do Programa de Pós-Graduação em Educação, Culturas e Identidades Fundação Joaquim Nabuco e Universidade Federal Rural de Pernambuco (Fundaj/UFRPE) e do Mestrado Profissional de Sociologia em Rede Nacional (ProfSocio/MEC). E-mail: rodrigues.cibele@gmail.com.

*** Doutora em Ciências da Educação pela Universidade da Madeira, Portugal (UMa/PT). Pesquisadora e Professora do Programa de Pós-Graduação em Educação, Culturas e Identidades Fundação Joaquim Nabuco e Universidade Federal Rural de Pernambuco (Fundaj/UFRPE) e do Departamento de Educação da Universidade Federal Rural de Pernambuco (UFRPE)/ Coordenadora do GEEAD/NEFOPP. E-mail: gildedufrpe@gmail.gov.
} 
how this policy is implemented in a primary school (initial years ) of the municipal network. For data collection, semi-structured interviews and observations were performed. As main results it was found that the model adopted in João Pessoa is centered on the expansion of time, from the perspective of the full-time student. The On Screen Project has visible influences from the More Education Program. In practice, the extension of hours is linked to social protection. But it is also organized from the discourse of standardized assessments by reinforcing the study of the curricular contents of Portuguese and mathematics, aiming at raising the averages in those disciplines. In addition, the secretariat has its own evaluation system that follows the same logic - the so-called School Note 10 Program. The subjects that perform teaching functions, especially the teachers and tutor are charged for the children to achieve the performance necessary to win the award of the Note 10 School Program, thus the work of the institution revolves in rules of the Program.

Keywords: Educational policy. Extension of the school day. Quality of education.

\section{RESUMEN}

\section{EL PROYECTO ESCUELA EN TIEMPO INTEGRAL EN EL MUNICIPIO DE JOÃO PESSOA-PB: CONTEXTOS Y PRÁCTICA}

El presente artículo objetiva analizar el contexto de implantación del Proyecto "Escuela de Tiempo Integral" en una escuela de enseñanza fundamental en la ciudad de João Pessoa-PB, así como comprender cómo esta política se efectúa en la práctica en una escuela de enseñanza fundamental (años iniciales de la red municipal. Para la recolección de datos se realizaron entrevistas semiestructuradas y observaciones. Como principales resultados se encontró que el modelo adoptado en João Pessoa está centrado en la ampliación del tiempo, en la perspectiva del alumno a tiempo completo. El Proyecto en pantalla tiene visibles influencias del Programa Más Educación. En la práctica, la extensión de la carga horaria está ligada a la protección social. Pero también se organiza desde el discurso de las evaluaciones estandarizadas para fortalecer el estudio de los planes de estudios de portugués y matemática, dirigido a elevar el promedio en esas disciplinas. Además, la secretaría posee un sistema propio de evaluación que sigue la misma lógica - el llamado Programa Escuela Nota 10. Los sujetos que desempeñan funciones docentes, en especial las profesoras y tutoras son cobradas para que los niños alcancen el desempeño necesario para ganar la premiación del Programa Escuela Nota 10, de modo que el trabajo de la institución gira en torno de las normas de dicho programa.

Palabras clave: Política educativa. Ampliación de la jornada escolar. Calidad de la educación.

\section{Introdução'}

A onda neoliberal dos anos 1990 ecoa até os dias atuais com a criação de programas focalizados

1 A realização da pesquisa ocorreu mediante a autorização da Secretaria Municipal de Educação da cidade de João Pessoa, bem como a assinatura do termo de livre consentimento de todos os sujeitos entrevistados, sendo resguardado o sigilo em relação ao nome da escola e dos entrevistados. em detrimento do direito à educação. O discurso se pauta em "necessidade" de direcionar ações especiais para os mais "vulneráveis", como se fosse o caminho para resolução de problemas mais amplos e sedimentados. Por outro lado, também se produziu uma narrativa em torno da "melhoria de resul- 
tados de aprendizagem" que se tornou a panaceia para resolução de todas as dificuldades das escolas públicas. Esses são alguns aspectos dos discursos produzidos pelos organismos internacionais que possuem reflexo nas subjetividades dos docentes, sobretudo em termos de regulação do seu trabalho (BALL, 2001). No marco dessa matriz discursiva está também a tese da ampliação da jornada escolar como forma de produzir melhores "resultados de aprendizagem", sobretudo entre os mais pobres, com um viés de assistência social (FANFANI, 2010; FELDEFBER, 2003; LLORENS, 2014; MARTINIC, 2015; VELEDA, 2013). Vale ressaltar que está resumido como "resultados de aprendizagem" um significante com sentidos diferenciados, tais como impactos em avaliações, mudanças de códigos culturais e influência na permanência nas escolas.

Como afirma Ball (2001), essas diretrizes globais são apropriadas de maneira diferenciada nos contextos locais; as distinções são atravessadas por essa gramática dominante. Partindo desse pressuposto, o presente artigo discute resultados de um estudo de caso realizado na rede municipal de João Pessoa-PB, buscando compreender as práticas discursivas do Projeto Escola de Tempo Integral, e como esta política é efetivada na prática em uma escola de ensino fundamental (anos iniciais) da rede municipal. O Projeto em tela foi implantado na rede municipal de João Pessoa no ano de 2011, "visando um atendimento educacional muito mais amplo e significativo para crianças e adolescentes que passam a ser atendidos pelas instituições educacionais [...], em uma jornada ampliada de dez horas diárias [...]" (JOÃO PESSOA, 2015). Seguindo a lógica dos programas pontuais, ele iniciou em apenas cinco de um total de 95 escolas. Nessa perspectiva, o objetivo é analisar, à luz da abordagem do ciclo de políticas (BALL; BOWE, 1992 apud MAINARDES, 2006), a implantação do referido Projeto. Sendo assim, o texto está estruturado em três seções: a primeira apresenta o percurso metodológico dessa pesquisa; a segunda exibe o contexto da formulação da política do Projeto Escola de Tempo Integral, apresentando os panoramas internacional, nacional e municipal que contribuíram nesse processo (o que os autores denominam de contexto da influência), bem como uma breve análise do texto da política; a terceira seção, por sua vez, expõe o contexto da prática na escola pesquisada, seguida das considerações finais.

\section{O caminho percorrido}

Trata-se de uma pesquisa de cunho qualitativo, que tem como estratégia o estudo de caso em escola de ensino fundamental (ANDRÉ, 2013). Para compreendermos o contexto da influência da formulação do Projeto foi entrevistada a ex-secretária de educação do Município de João Pessoa (que estava à frente da secretaria na época da implantação do projeto). Além disso, no corpus da pesquisa foram incluídos os documentos da política para análise dos seus textos. Para atingir o objetivo do estudo, utilizou-se a observação do trabalho docente e 34 entrevistas semiestruturadas. Foram 33 sujeitos que desempenhavam a função docente na escola pesquisada, como protagonistas na atuação da política. Ao longo da análise buscou-se identificar os significados, analisando as interações, compreendendo e interpretando linguagens.

Nessa perspectiva, o campo dessa pesquisa foi uma escola da rede municipal de João Pessoa que possui o Projeto Escola de Tempo Integral. Os critérios que levaram à escolha foi o fato de a escola fazer parte do Projeto desde o início (em 2011), assim como o fato de ela ter sido construída objetivando o funcionamento em tempo integral.

\section{Conhecendo os contextos: Projeto Escola de Tempo Integral}

O Projeto Escola de Tempo Integral surge em um contexto de propagação da ampliação do tempo escolar que, por sua vez, está imersa em um contexto de política de programas, que provém de um cenário mais amplo das reformas educacionais dos anos 1990 em toda a América Latina (JESUS; BORGES, 2016). Essa reforma, segundo Casassus (2001), foi orientada pelas organizações internacionais, dentre as quais estão o Banco Mundial, a Organização das Nações Unidas para Educação, Ciência e Cultura (Unesco), o Fundo das Nações Unidas para a Infância (Unicef), estabelecendo uma agenda globalizada para as políticas (BALL, 2001). 
Esse cenário é importante para que possamos identificar as bases de construção dos discursos políticos, considerando a dialética entre os contextos global e local (MAINARDES, 2006).

Os objetivos estruturantes da reforma são diversos, podendo-se destacar pelo menos três. Primeiro, situar a educação e o conhecimento no centro da estratégia de desenvolvimento por sua contribuição tanto econômica quanto social; para isso a estratégia foi direcionar mais recursos financeiros para o setor educacional. Segundo, iniciar uma nova etapa de desenvolvimento educacional mediante a mudança de gestão, com o processo de descentralização e a ênfase na qualidade e na equidade. Terceiro, melhorar os níveis de qualidade de "aprendizagem" por meio de ações nos âmbitos macro e micro, com a instalação de sistemas nacionais de avaliação e o desenvolvimento de programas compensatórios de discriminação positiva e proposição de uma reforma curricular (CASASSUS, 2001).

Vale ressaltar que existe um grande debate em torno dos sentidos atribuídos aos termos "qualidade" e "aprendizagem". Eles são objeto de lutas políticas no campo educacional. Na perspectiva da reforma, a qualidade da educação está pautada na valorização de práticas de competição e empreendedorismo, fundamentadas no discurso liberal no qual os indivíduos são autorreferenciados (RODRIGUES; CASTRO; CUNHA JÚNIOR, 2017). De acordo com Ball (2006), as reformas aconteceram na lógica do novo gerencialismo envolvendo processos de privatização e imprimindo a hegemonia dos discursos de excelência e efetividade como sinônimos de qualidade.

O conceito de qualidade, com viés economicista, foi absorvido pelo campo da educação e segue sendo bastante utilizado em pesquisas e projetos do governo, simbolizando a aferição de padrões e metas exigidos pelos Planos vigentes). No Brasil, teve início com o Sistema de Avaliação da Educação Básica (SAEB), criado na década de 1990. Um sistema de avaliação amostral com instrumentos de aferição de resultados e controle, seguindo a tendência mundial de avaliação quantitativa da educação (BONAMINO; FRANCO, 1999).

Nesse cenário, a ampliação do tempo escolar emerge também como uma possibilidade de melhoria da qualidade de educação na América Latina.
A Unesco, em vários documentos, defende que o tempo é um dos fatores que mais possuem impacto na qualidade da aprendizagem (PREAL, 2002). Entre o final dos anos 1990 e início do século XXI, diversos países passaram a criar escolas de tempo integral, a exemplo de Chile, Uruguai e Venezuela, no final da década de 1990. Mais tarde, nos anos 2000, Cuba e México implantaram a ampliação da jornada escolar. Em 2011, a Argentina criou um Programa de Jornada de Tempo Completo - embora já existissem escolas de tempo integral em menor proporção (VELEDA, 2013).

É importante destacar que as concepções que fundamentam a política ampliação da jornada escolar nos países citados são distintas, como também os modelos de implantação, que variam entre universal e focalizado. Mesmo existindo diferenças das políticas do aumento da jornada escolar, há, segundo Veleda (2013), três eixos comuns entre elas. Primeiro, a ampliação está atrelada à proteção social em contexto de desigualdade e de incorporação das mulheres ao mercado de trabalho. Segundo, o discurso da melhoria dos resultados de aprendizagem, tendo como parâmetro as avaliações nacionais e internacionais. Terceiro, a influência de pesquisas e as transformações próprias da educação fundamental fizeram surgir um discurso em torno da necessidade de garantir saberes fundamentais e abarcar a complexidade da cultura contemporânea, incluindo novas aprendizagens, como línguas estrangeiras e novas tecnologias de comunicação. Por essas razões, o aumento dos conteúdos precisaria de um tempo maior para o processo de ensino.

No tocante ao Brasil, o ano 2007 foi um divisor de águas nas políticas educacionais. O Governo Lula, sob a coordenação do ministro Haddad, criou um conjunto de políticas que denominou Plano de Desenvolvimento da Educação. Pela primeira vez na história, o Governo instituiu programas que atendiam desde a educação infantil até a pós-graduação, passando por especificidades como a ampliação da jornada.

Nesse contexto de reformas, houve a criação do Índice de Desenvolvimento da Educação Básica (IDEB), uma referência desenvolvida no Governo Lula para servir de indicador de qualidade na educação. O IDEB mede o desempenho dos alunos (em português e matemática) e o fluxo (evasão e 
distorção idade-série), estabelecendo uma escala que vai de zero a dez, para mostrar as condições de ensino no Brasil (OLIVEIRA, 2009). Partindo da análise dos indicadores do IDEB, o MEC ofereceu apoio técnico e financeiro aos municípios com índices insuficientes de qualidade de ensino (OLIVEIRA, 2009), por meio do Plano de Ações Articuladas (PAR), dentro de uma lógica de planejamento estatal e de garantia da equidade.

Dentre as ações do PAR estava o Programa Mais Educação (PME), instituído pela Portaria Interministerial $n^{\circ} 17 / 2007$ (BRASIL, 2007), que tinha como foco principal ofertar atividades no contraturno para escolas do ensino fundamental, iniciando um processo de ampliação da jornada, nos moldes de uma política focalizada. Em 2008, o Programa credenciou 1.380 unidades de ensino. Usou como critérios: escolas contempladas com PDDE/Integral no ano de 2008 e 2009; escolas com baixo IDEB e/ ou localizadas em zonas de vulnerabilidade social; escolas situadas nas capitais e nas cidades das nove regiões metropolitanas, bem como naquelas com mais de 90 mil habitantes (BRASIL, 2016). Tais critérios ratificam o discurso dessa ampliação para diminuir a vulnerabilidade, mas em um contexto de um Governo com diversas políticas que também apontavam para o discurso do direito à educação. A cada ano esses números foram aumentando gradativamente. Atingiu, na adesão de 2014, a marca de mais de 56 mil escolas credenciadas. No entanto, não houve adesão em 2015, tendo sido executado apenas nas escolas que ainda possuíam recursos remanescentes.

O PME foi criado a partir das experiências históricas de escolas em tempo integral, como as escolas-parque criadas por Anísio Teixeira e os CIEPs $^{2}$ criados por Darcy Ribeiro (MOLL, 2012).

2 Centro Integrado de Educação Pública foi implantado por Darcy Ribeiro, quando ocupou o cargo de Secretário de Educação do Rio de Janeiro, na gestão do governador Leonel Brizola. Darcy entendia que a ação educativa escolar só atenderia aos princípios de educação integral quando realizada em tempo integral, fazendo uma crítica ferrenha à segmentação dos turnos escolares. Os Centros Integrados de Educação Pública estavam localizados em áreas de população carente e ofereciam uma educação integral e em tempo integral, onde as crianças permaneciam por toda a manhã e tarde, tendo oportunidade de realizar diferentes atividades como: aulas, práticas de educação física, atividades artísticas, estudo dirigido, vídeos, visitas à biblioteca, utilização de computadores, atividades com animadores culturais e práticas para $\mathrm{o}$ desenvolvimento de uma vida saudável (MONTEIRO, 2009).
Ao longo de sua existência (entre 2007 e 2015), o PME foi sendo construído e se configurando como uma ação indutora para a ampliação da jornada e a reorganização curricular na perspectiva da educação integral. Somente em 2010 essa postura se materializa no Decreto ${ }^{\circ} 7.083 / 2010$ (BRASIL, 2010) que também considera o programa como ação para a "melhoria da aprendizagem" (MOLL, 2010).

Embora tivesse uma concepção integral de educação que buscava disseminar, convivia com o fato de suas atividades serem desenvolvidas por meio de oficinas, realizadas no contraturno das "aulas regulares". A recomendação era que o Programa Mais Educação fosse somado à proposta pedagógica da escola, proporcionando uma articulação entre os conteúdos escolares e as atividades das oficinas, visando uma educação integral. Contudo, as pesquisas mostram que essa articulação não acontecia na maioria das escolas (RODRIGUES et al, 2018).

Um dos aspectos estruturantes da proposta do Programa Mais Educação, de acordo com Jaqueline Moll (2012, p. 133),

[...] é sua preocupação em ampliar a jornada escolar modificando a rotina da escola, pois sem essa modificação pode-se incorrer em mais do mesmo, sem que a ampliação do tempo expresse caminhos para uma educação integral. Esse aspecto refere-se ao esforço para contribuir no redimensionamento da organização seriada e rígida dos tempos na vida da escola, contribuição essa reconhecida nos conceitos de ciclos de formação que redimensionam os tempos de aprendizagem e de cidade educadora, território educativo, comunidade de aprendizagem que pautam novas articulações entre os saberes escolares, seus agentes (professores e estudantes) e suas possíveis fontes.

Nesse sentido, o referido programa absorve contribuições teórico-conceituais de educação integral que existem desde as contribuições de Anísio Teixeira, Darcy Ribeiro, Paulo Freire, do movimento das cidades educadoras e de muitas experiências que marcaram esse histórico da educação integral e em tempo integral no nosso país.

O rol de atividades era classificado a partir do que se denominou como macrocampos: acompanhamento pedagógico; educação ambiental e desenvolvimento sustentável; esporte e lazer, 
educação em direitos humanos; cultura, artes e educação patrimonial; cultura digital; promoção da saúde; comunicação e uso de mídias; investigação no campo das ciências da natureza (BRASIL, 2012).

Outro aspecto que contribuiu para o debate da ampliação da jornada escolar e da realização de uma educação integral foi à aprovação do atual Plano Nacional de Educação - PNE 2014-2024 (BRASIL, 2016). Desse modo, os estados e os municípios foram impulsionados a elaborarem planos estaduais e municipais de educação, à luz do plano nacional. Várias proposições foram feitas em níveis nacional, estadual e municipal, com o intuito de alcançar a meta 6 do PNE, que trata da ampliação da jornada escolar.

\section{Contexto Municipal das escolas de tempo integral}

O Projeto Escola de Tempo Integral foi implantado no Município de João Pessoa no ano de 2011, na gestão do ex-Prefeito Ricardo Coutinho (atual Governador do Estado da Paraíba). Esse período coincide com o ano posterior à publicação do decreto que tenta induzir políticas de educação em tempo integral.

Segundo a ex-Secretária, ao assumir o posto, ${ }^{3} \mathrm{O}$ primeiro passo foi elaborar um plano que orientasse as ações da Secretaria, tendo como objeto a sala de aula, almejando a melhoria das relações ensino-aprendizagem. Tendo em vista que, conforme relatou, "ter um professor universitário à frente da educação municipal é um ganho muito grande, considerando que as instituições (universidade e secretaria de educação) estariam envolvidas não só na formação dos professores que iriam para a rede municipal, como também passaria a interferir nas decisões e nas ações que iriam acontecer nessa rede" (EX-SECRETÁRIA DE EDUCAÇÃO DO MUNICÍPIO DE JOÃO PESSOA).

3 A ex-Secretária entrevistada é professora universitária lotada na Universidade Federal da Paraíba e assumiu a Secretaria Municipal de Educação no ano de 2007, a convite do então Prefeito Ricardo Coutinho. Ela ficou à frente da Pasta da Educação durante cinco anos. Três anos e meio na gestão de Ricardo Coutinho e um ano e meio na gestão de Luciano Agra - Vice-Prefeito que assumiu a prefeitura em 2011, quando Ricardo se afastou para se candidatar ao governo do estado da Paraíba.
Antes de iniciar o Projeto Escola de Tempo Integral, a ex-Secretária explicou que foram realizadas algumas ações, que contribuíram para organizar o cenário da educação municipal, quais sejam, a criação do projeto Apoio Pedagógico, ${ }^{4}$ a formação continuada, o Programa Escola Nota 10. ${ }^{5}$ Ainda de acordo com ela, a formação passou a ser ministrada por profissionais das instituições de ensino superior. Atrelada a essa formação foi criado o programa Escola Nota 10, que é pautado na lógica da bonificação, porque visa conferir o prêmio do $14^{\circ}$ salário para os profissionais da educação de João Pessoa. Para ter direito ao bônus, os critérios são a participação dos docentes na formação continuada e o desempenho dos alunos na avaliação externa aplicada pela Secretaria. A menos de um ano da implantação da avaliação por meio do IDEB, a própria Secretaria criou uma "avaliação" específica, seguindo o discurso do novo gerencialismo.

Numa perspectiva que articula a lógica da nova gestão pública com a tradução local, a Secretaria de Educação cria o Projeto Ano Cultual, que se pauta no discurso da suposta integração entre a educação escolar e a cultura local. Nesse projeto, se escolhia um artista paraibano para ser homenageado. Acoplado ao projeto, criou-se um concurso chamado de Estudante Destaque, ação que previa a produção textual dos alunos sobre as atividades do Ano Cultural. O aluno que fizesse a melhor produção de texto ganhava prêmios tais como notebook, flau-

4 "Os estudantes da universidade, no caso a Universidade Federal da Paraíba, eles eram selecionados a partir de critérios, como a gente faz aqui, em relação a quem tem bolsa; eles iam pra sala de aula acompanhar o professor e acompanhar a aprendizagem dos alunos. Então ele ficava quatro dias por semana na sala de aula, acompanhando o professor, e um dia aqui na universidade recebendo orientações e trazendo informações pra gente né?! Aliás, pros professores que orientavam, a situação individual dos alunos. Então, assim, isso foi uma coisa muito importante, porque a gente acha que do ponto de vista da formação desses alunos que tiveram acesso a esse tipo de trabalho né?, foi muito importante pra eles compreenderem um pouco e entender que eram capazes de aprender. Então, assim, através de pequenas mudanças até... tem relatos da época que diziam assim, que o estudante chegou pra professora aqui na universidade e disse: 'Professora, se a gente mudar aquela criança daquele lugar que ela tá e botar na primeira fila, ele vai render mais.' Então, assim, medidas simples foram sendo tomadas". (EX-SECRETÁRIA DE EDUCAÇÃO DO MUNICÍPIO DE JOÃO PESSOA).

5 O Programa Escola Nota 10 foi instituído no Município de João Pessoa pela Lei $\mathrm{n}^{\circ} 11.607$, de 23 de dezembro de 2008, e será melhor explicado nas seções posteriores. 
ta, violão, filmadoras, MP4, dentre outros. Nesse âmbito também se criou um programa chamado História da Paraíba, com estudantes dos cursos de História, Turismo e Geografia levando os alunos do $9^{\circ}$ ano do ensino fundamental à $3^{\mathrm{a}}$ série do ensino médio para conhecer a história da cidade de João Pessoa e da Paraíba, por meio de aulas de campo e vivências em diversos locais históricos da cidade de João Pessoa.

Funcionavam nessa época os Programas Ciranda Curricular (programa municipal) e Escola Aberta e Mais Educação (de iniciativa federal), que tiveram grande influência na concepção do Projeto Escola de Tempo Integral. Nesse contexto, pode-se perceber que o Programa Mais Educação cumpriu seu papel de ação indutora para a política de educação integral (MOLL, 2012). Segundo a ex-Secretária, também surgiu por causa do interesse do então prefeito ${ }^{6}$ em efetivar a posposta do tempo integral.

Também ficou claro que a concepção do projeto é o aluno integral (CAVALIERE, 2009).

Em termos de concepção é... escola em tempo integral mais na perspectiva de um aluno integral e de uma criança integral. Ele estava na escola não só enquanto aluno, ele tava enquanto uma criança, que deve ter acesso aos conteúdos, mas que deve ter acesso também à arte, a cultura, ao esporte e a toda educação ambiental, enfim, tudo aquilo que vai fazer dele um cidadão diferenciado, né?! (EX-SECRETÁRIA DE EDUCAÇÃO DO MUNICÍPIO DE JOÃO PESSOA, grifo nosso).

Segundo Cavaliere (2009, p. 53), nas propostas que possuem como referência o aluno em tempo integral a "ênfase estaria na oferta de atividades diversificadas aos alunos no turno alternativo ao da escola, fruto da articulação com instituições multissetoriais, utilizando espaços e agentes que não os da própria escola, pretendendo propiciar experiências múltiplas e não padronizadas". O contraponto é a proposta da escola de tempo integral, com "ênfase no fortalecimento da unidade escolar, com mudanças em seu interior pela atribuição de

6 Frente à informação que Ricardo foi o entusiasta do Projeto Escola de Tempo Integral, houve várias tentativas de contato para entrevistá-lo. A princípio a secretária dele afirmou que Ricardo contribuiria com a pesquisa, porém, no dia agendado para tal, informou-se que devido à sua agenda de atribuições enquanto governador ficaria inviável a participação dele nesse estudo. novas tarefas, mais equipamentos e profissionais com formação diversificada, pretendendo propiciar a alunos e professores uma vivência institucional de outra ordem" (CAVALIERE, 2009, p. 53). No contexto educacional brasileiro as experiências de "ampliação do tempo escolar estão baseadas tanto em concepções autoritárias ou assistencialistas como em concepções democráticas ou que se pretendem emancipatórias" (CAVALIERE, 2009, p. 51).

Nesse sentido, objetivando o atendimento ao aluno em tempo integral, a ex-Secretária informou que a rotina da escola de tempo integral tinha a seguinte organização do tempo:

Às 7 horas começavam as aulas, 9 horas tinha 0 intervalo para o lanche, é... o professor... tinha professor tutor, porque não era só você ter os professores das disciplinas, de conteúdo, mas tem de ter um professor tutor que vai dar uma certa organicidade ao funcionamento dessas... entrosar essas atividades. É... $11 \mathrm{~h} 30$ era servido o almoço e aí a gente sempre separava, 11 h30 era 0 almoço pra ensino fundamental, que são criançinhas pequenas, e muitas vezes pra evitar... mal entendido e as crianças às vezes criavam confusões. Antes dava todo mundo junto, mas depois a gente resolveu estabelecer diferenciação, e 11 h45 começava o almoço pros meninos do ensino fundamental 2. Treze horas começava a realização das tarefas escolares e aí era feita através de reforço com esses tutores que chegavam as $10 \mathrm{~h} 45$, pra justamente dar a ideia de receber dos professores que já tinham ministrado aula, o que é que tinha sido é... ministrado, naquele dia, naquele conteúdo e aonde tinha apresentado a maior dificuldade pra eles, então assim, das... das 13 horas até as 15h30, era o momento de, digamos assim, não diria reforço não, mas, seria o momento em que haveria correção de exercício, a tentativa de melhorar... a aprendizagem dos alunos né?! E $15 \mathrm{~h} 30$ começavam as oficinas pedagógicas. (EX-SECRETÁRIA DE EDUCAÇÃO DO MUNICÍPIO DE JOÃO PESSOA, grifo nosso).

A divisão do trabalho entre professores e tutores foi justificada pela ideia de que "precisava" de um profissional que pensasse o aluno integral, acompanhando-o no tempo ampliado, tendo em vista que, segundo ela, os professores ainda têm a visão de estar na escola para ministrar aulas. Essa 
ideia de tutor $^{7}$ vem dos monitores tanto do Programa Mais Educação quanto do Programa Escola Aberta. Diferente desses programas citados, para a implantação do Projeto Escola de Tempo Integral algumas escolas foram construídas para este fim e outras foram adaptadas.

Diferentemente também do Programa Mais Educação, que tinha uma série de cadernos orientadores para a prática nas escolas, não houve a produção de documentos oficiais sobre a concepção e o modus operandi do projeto. Essa informalidade ainda impera nas ações realizadas pela prefeitura. Sendo assim, a política das escolas de tempo integral só se materializou em textos em 2015, no Plano Municipal de Educação do Município de João Pessoa (PMEJP) - Lei $n^{\circ} 13.035$, de 19 de junho de 2015 (JOÃO PESSOA, 2015a), e na Resolução $\mathrm{n}^{\circ} 008$ de 07 de abril de 2015 (JOÃO PESSOA, 2015b), do Conselho Municipal de Educação, que dispõe sobre as diretrizes para organização e funcionamento das Escolas de Tempo Integral. O referido Plano justifica que vem desenvolvendo ações no intuito de conseguir a meta de $50 \%$ das escolas públicas em tempo integral, conforme orientado no Plano Nacional de Educação 2014-2024.

Seguindo também a lógica dos "programas" em detrimento das políticas, o Projeto iniciou-se em 2011, em cinco escolas, duas delas construídas com uma estrutura já para a jornada ampliada, e as outras três foram adaptadas. De acordo com as informações do Plano Municipal de Educação de João Pessoa (PMEJP), das 95 escolas que compunham a rede municipal em 2015, 16 são de tempo integral.

No ano de 2018, com o lançamento da Diretriz Normativa para as escolas de tempo integral, o referido documento expõe, em dados numéricos, o crescimento da quantidade de escolas em tempo integral. No ano de 2012, a quantidade de escolas cresceu de cinco para doze; em 2014, passou para 14 escolas; em 2015 se contabilizavam 16 escolas em tempo integral; em 2017 esse número subiu para 19; e em 2018 totalizam 26 escolas em tempo

7 Para ser tutor da Escola de Tempo Integral, conforme relatou a ex-Secretária, realizava-se uma seleção, muito mais pelo perfil das pessoas. Tinha-se uma conversa com a direção da escola para saber se algum profissional da própria instituição tinha o perfil e o interesse de assumir tal cargo; caso não houvesse, procedia-se com a análise de currículos e as entrevistas. integral. Desse total de 26 escolas, três delas foram construídas entre os anos de 2016 e 2018, com o objetivo de fazer parte do Projeto, totalizando cinco escolas construídas para este fim, de 2011 a 2018.

\section{A escola de tempo integral: efetivação da política na prática}

A Escola Municipal TEI está localizada na zona sul da cidade e foi construída em 2011, na gestão no ex-Prefeito Ricardo Coutinho, com o objetivo de funcionar como escola de tempo integral. ${ }^{8}$ Por essa razão, a escola tem uma estrutura ampla, seu ambiente físico está organizado em dois andares, com uma arquitetura adequada para acessibilidade, como também organizada de forma que possibilita a comunicação entre tais andares, sem necessariamente ter que se deslocar para eles. ${ }^{9}$

Diante do exposto, a Escola Municipal TEI dispõe de uma estrutura física bem satisfatória ao se comparar com o universo das escolas públicas e privadas que oferecem ensino fundamental no Brasil, contudo falta a devida manutenção dos espaços. Segundo as notas estatísticas do Censo Escolar de 2016, divulgadas pelo INEP, apenas $44,7 \%$ das escolas possuem laboratório de informática; $49,2 \%$ têm sala de leitura ou biblioteca, 97,1\% possuem banheiro dentro do prédio e 33\% delas apresentam banheiro adaptado para acessibilidade; $43,9 \%$ possuem pátio coberto; $8,8 \%$ têm auditório e apenas $35,5 \%$ dispõem de quadra de esporte (BRASIL, 2017). Faz-se necessário considerar que a qualidade da educação não depende apenas da infraestrutura, mas é algo que conta bastante quando se entende que a educação é um direito, e se comparado ao que se tem disponível para os alunos da rede pública e privada (RODRIGUES; CASTRO; CUNHA

8 A inauguração da Escola Municipal TEI ocorreu em 2012, pelo ex-Prefeito Luciano Agra, que era Vice-Prefeito e assumiu a Prefeitura porque o Prefeito se afastou para concorrer às eleições para o Governo do Estado da Paraíba.

9 Possui 13 salas de aula, uma secretaria, uma diretoria, 6 banheiros (4 para crianças e 2 para funcionários), uma sala de vídeo (também chamada de miniauditório), 2 bebedouros (um em cada andar), sala de professores, sala para especialistas (coordenador, orientador educacional, psicólogo e assistente social), almoxarifado, biblioteca, cozinha, refeitório, espaço para higienização bucal, dispensa, espaço com areia, quadra com xadrez humano, minicampo para futebol, um ginásio poliesportivo, um laboratório de informática e uma sala para Atendimento Educacional Especializado (AEE). 
JÚNIOR, 2017). ${ }^{10}$

Ao realizar a pesquisa na Escola, reportando o olhar para os profissionais que desempenham a função docente nessa instituição (essa estrutura se repete no projeto nas outras escolas), foram encontrados três tipos de perfis, quais sejam, professor de atividades curriculares, professor tutor e oficineiro. Segundo o Projeto Pedagógico da referida Escola, os professores de atividades regulares são responsáveis pelo ensino das disciplinas no turno da manhã; os professores tutores devem acompanhar os alunos nas atividades de socialização e atividades de reforço (desde o horário do almoço até o fim da tarde); e os oficineiros são incumbidos do desenvolvimento de atividades esportivas e artístico-culturais das oficinas.

$\mathrm{Na}$ prática acontece da seguinte forma: para cada turma da escola têm-se uma professora regular no turno da manhã e uma tutora que fica com a turma no turno da tarde. Assim, os alunos possuem a referência dessas docentes específicas. Em algumas salas foi visto que os alunos demonstram mais afeição e respeito pelas tutoras do que pelas próprias professoras. Foi visto que existe interação entre as professoras e tutoras, apenas uma das professoras demonstrou resistência em relação à tutora da sua turma. ${ }^{11}$

Frente ao que pode ser observado na Escola Municipal TEI, percebe-se que a organização do tempo escolar e dos cargos dos profissionais que desempenham a função docente tem influências visíveis do modelo do Programa Mais Educação.

\section{Reflexões sobre o cenário encontrado: a contradição entre a autonomia e a regulação na ação docente}

Segundo Santos e Duboc (2004, p. 119), "a auto-

10 No tocante ao funcionamento e atendimento, a Escola funciona em três turnos: pela manhã e à tarde atende a crianças com faixa etária de seis a dez anos em tempo integral (embora tenha alunos com 12 anos, que estão fora de faixa). Tais crianças chegam à instituição às $7 \mathrm{~h}$ e saem às $17 \mathrm{~h}$. Ao todo são 313 estudantes que ficam em tempo integral. No turno da noite têm-se as turmas dos ciclos que correspondem à educação de jovens de adultos (EJA), em nível fundamental.

11 Há também na Escola Municipal TEI a presença de cuidadoras que acompanham as crianças portadoras de deficiências. Entretanto, optou-se por não incluir as cuidadoras entre as entrevistadas porque entraria em outra discussão teórica, da "educação especial", que não é o foco da pesquisa. nomia pressupõe uma autogestão do conhecimento pelo grupo dos pares, bem como o autocontrole das práticas", porém a autonomia docente no contexto escolar vem passando por transformações, principalmente a partir das reformas educacionais dos anos de 1990, que trouxeram implicações para a educação pública no tocante a sua organização e gestão, elegendo a escola como núcleo de planejamento e gestão (OLIVEIRA, 2004). Nesse sentido, se configurou a descentralização em direção ao nível local, promovendo a escola mais autônoma e, consequentemente, ampliou-se as responsabilidades e o espaço de decisão em nível escolar (GOROSTIAGA; VIEIRA, 2011).

Os docentes, nesse processo, passaram a ser agentes responsáveis pelo desenvolvimento das ações da reforma no contexto escolar, à medida que efetivam as propostas e programas educacionais. Alejandra Birgin (2000 apud TELLO, 2011) explica que se observa um retorno a uma política mais explicitamente voltada para os docentes em termos de avaliação do desempenho, prêmios, salários atrelados a resultados, como incentivo à produtividade.

É justamente nesse contexto de alcance de resultados e prêmios financeiros de incentivo que acontece o trabalho docente dentro do Projeto Escola de Tempo Integral e nas escolas municipais de João Pessoa.

O Programa Escola Nota 10 foi instituído no Município de João Pessoa pela Lei ${ }^{\circ} 11.607$, de 23 de dezembro de 2008, na mesma gestão que instituiu o Projeto de Escolas de Tempo Integral (de Ricardo Coutinho), com a finalidade de contribuir para a elevação do nível de aprendizagem dos alunos da Rede Municipal de Ensino do Município de João Pessoa (JOÃO PESSOA, 2008). O art. $2^{\circ}$ da referida lei explica que

O PROGRAMA ESCOLA NOTA 10 concede aos trabalhadores e profissionais em educação um prêmio baseado na valorização do desempenho pedagógico e funcional, mediante avaliação anual das Escolas Municipais de Ensino Fundamental - EMEFs, no âmbito da Secretaria Municipal de Educação e Cultura - SEDEC, obedecidos os requisitos estabelecidos na presente lei e a pontuação mínima definida em regulamentação. (JOÃO PESSOA, 2008). 
Segundo a Lei n ${ }^{\circ} 11.607 / 2008$, são objetivos do referido programa:

I - incentivar o desenvolvimento educacional e mobilizar as Escolas Municipais de Ensino Fundamental, com a finalidade de melhorar a qualidade da educação no município de João Pessoa; II - reconhecer e premiar os trabalhadores e profissionais em educação de cada Escola Municipal de Ensino Fundamental que apresentarem resultados globais de acordo com a média estabelecida, considerando as metas definidas; III - apresentar os resultados alcançados pelas Escolas Municipais de Ensino Fundamental e divulgá-los através de publicidade institucional. (JOÃO PESSOA, 2008).

Nesse contexto, são estabelecidas ações que devem ser realizadas pela escola para ganhar a premiação, que é o pagamento do $14^{\circ}$ salário a todos os funcionários que trabalham na instituição. Ao indagar os sujeitos que desempenham a função docente sobre a autonomia para o desenvolvimento das ações no ambiente escolar, eles relataram unanimemente que planejam e desenvolvem as suas ações com a autonomia necessária. Contudo, esse planejamento e essas ações acontecem objetivando o alcance de resultados para conseguir alcançar e ganhar a premiação do Programa Escola Nota 10, como pode se observar no relato:

No município tudo gira em torno do... do projeto Escola Nota Dez, né?! E aí, todos os projetos da escola são desenvolvidos em torno desse projeto maior do município. E tudo é registrado, é fotografado, é... tem as formações... Tudo pra que a escola apresente um bom rendimento né?! E o objetivo da escola é tirar realmente a nota dez. Mas pra tirar a nota dez não pode ter nada fora do lugar (...) Bom, essa nota dez é composta de vários itens, né?! As cadernetas têm que tá todas impecáveis, em dia. É... aí vem as formações que a gente tem que participar, que a gente não pode ter falta... (...) No máximo, se não me engano, por questão de doença, tem que estar justificado, com atestado, duas faltas na formação, se faltar a terceira você já perde a formação e já baixa a nota da escola. E a outra parte é o rendimento dos alunos... eles vêm e aplicam uma prova no final do ano, pra ver como é que os alunos estão. $E$ juntando tudo isso aí, se não me engano tem outras coisas que eles vêm também avaliar, tem cozinha, merenda, estrutura da escola, tudo isso entra na nota. $E$ aí a gente realmente tem que ser uma escola de qualidade, se quiser tirar a nota dez. (PROFESSORA DO $3^{\circ}$ ANO A, grifo nosso).

De modo geral, todos se sentem cobrados a fim de atender ao que é exigido para que o coletivo seja beneficiado, mas as professoras e as tutoras são as que mais sentem essa cobrança, principalmente no tocante aos resultados do desempenho dos alunos na avaliação externa que é aplicada pelo município e conta muito para a pontuação no Programa Escola Nota 10. É por meio desse resultado que o trabalho das professoras e tutoras é avaliado. Além disso, desenvolvem testes simulados para "treinar" para essa avaliação. Esse "ajustamento" ao processo avaliativo é o que relatam professoras e tutoras:

A Secretaria da Educação constantemente passa pra ver a questão de diário, aí tem aquela questão do Nota 10, né?! que... é... que de certa forma é um incentivo, mas não deveria ser assim, por meritocracia, né?! Tem um... constantemente tem o acompanhamento das atividades, projeto, atividades, é... projeto de leitura, é... e essa questão do nível do aluno, né?!, se evoluiu, se não evoluiu, que é tudo em cima do diário, entendeu?! E faz, a gente faz é... constantemente a gente faz simulados, até $1^{\circ}$ ano também. É pra... acompanhamento nosso. Mas que os dados são passados pra Secretaria. Porque, assim, a questão do professor, a gente é muito cobrada. Já tem a questão de diário, de acompanhamento, que é bem descritivo, entendeu?! E todas as atividades que a gente faz, a gente tem que fazer relatório, mandar pros especialistas, tirar foto, entendeu?! é... fazer um descritivo de como foi... tutor não é cobrado isso. (PROFESSORA DO $1^{\circ}$ ANO A, grifo nosso).

Então, se você tirar o dez, você recebe o décimo quarto salário integralmente. Entendeu? $\mathbf{E}$ ninguém quer perder, né?! $\mathrm{E}$ a gente realmente tenta fazer o máximo que pode pra que atenda a todos os requisitos exigidos pela prefeitura. $\mathrm{Sim}, \operatorname{sim}$... A cobrança vem da prefeitura, todo mundo. $O$ diretor, até o faxineiro, a gente é extremamente cobrado. (PROFESSORA DO $3^{\circ}$ ANO A, grifo nosso).

Com certeza, muito cobrada mesmo, é como eu já tinha falado pra ti, como a gente é tutora e tem esse reforço escolar, a gente é muito, muito cobrada mesmo com o desempenho deles. Acho que a parte maior da cobrança que a gente tem é sobre isso. (TUTORA DO $5^{\circ}$ ANO A, grifo nosso). 


\section{E a pressão em cima de mim, de uma Escola Nota} 10 e Prova Brasil [...] Lógico que eu não vou deixar de fazer meu trabalho, porque eu me cobro mais. Mas é uma coisa assim, né?! Parece que é por hora, é o que tá acontecendo agora, não pensa no depois. (PROFESSORA DO $5^{\circ}$ ANO B, grifo nosso).

É. Nós nos empenhamos muito, entendeu?! A gente nunca tirou uma nota baixa não, sempre tirou 10. (TUTORA DO $2^{\circ}$ ANO A, grifo nosso).

Diante dos relatos têm-se a compreensão de dois fatores. O primeiro é que, de acordo com Arroyo (2012), muitas redes de ensino desvirtuam o sentido da ampliação do tempo, levando a instituição que atua em tempo integral a entrar na lógica que rege o seletivo sistema de ensino, baseando-se na política nacional de avaliação por resultados, a qual gera comparações competitivas entre as escolas, que se empenham em alcançar os objetivos estabelecidos para alcançar os prêmios, incentivos aos mestres, bônus, como também por medo de sofrer sanções por não conseguir atingir. $\mathrm{O}$ referido autor ainda expõe que

Encontramos escolas e redes de ensino que orientaram esse mais tempo, mas educação para reforçar o treinamento dos estudantes para sair-se bem nas ameaçadoras provinhas, provas, provões, para elevar a média e passar na frente das outras escolas e de outras redes de ensino. Mais lamentável ainda, aproveitar o turno extra para que os docentes não sejam punidos pelos baixos resultados de seus estudantes, para que, aumentando as médias nas avaliações por resultados, sejam merecedores de bônus. (ARROYO, 2012, p. 34).

O segundo é quanto à responsabilização dos docentes pelo sucesso e/ou fracasso dos programas educacionais. Essa questão se põe em evidencia a partir da década de 1990, pelo imperativo do processo de globalização e política neoliberal, que impulsionam várias reformas educacionais buscando atender as transformações ora impostas. As reformas são baseadas na capacidade de gestão e performatividade (BALL, 2002). Essa capacidade de gestão está fundamentada em um novo gerencialismo, centrado nas pessoas, as quais são formadas a partir de um espírito empreendedor, motivadas a produzir qualidade pelo esforço a excelência de si mesmos (BALL, 2006).
[...] a performatividade é alcançada mediante a construção e publicação de informações e de indicadores, além de outras realizações e materiais institucionais de caráter promocional, como mecanismos para estimular, julgar e comparar profissionais em termos de resultados: a tendência para nomear, diferenciar e classificar. (BALL, 2005, p. 544).

Esteve (2014) também expõe que grande parte da sociedade, alguns meios de comunicação e alguns governantes têm essa percepção simplista e linear de que os professores são responsáveis diretos do sistema de ensino e com isso também são responsáveis por todas as lacunas, fracassos, imperfeições e males que nele existem. Enquanto isso, o Estado se limita à elaboração de políticas, notadamente no plano curricular (símbolo da unidade e da integridade de um "sistema" educativo), e pela instalação de mecanismos de avaliação que controlam a conquista dos objetivos determinados (LESSARD; TARDIF, 2008).

Para alcançar tais objetivos determinados, Alves Garcia e Barreto (2006 apud TELLO, 2011) argumentam que o governo busca atingir a subjetividade e as emoções dos docentes, fazendo com que tais sujeitos criem um senso de autorresponsabilização e culpa, corroborando com o que Ball (2006) expõe sobre performatividade. Portanto, percebe-se que a "autonomia docente" no Projeto Escola de Tempo Integral é balizada pelo Programa Escola Nota 10.

De modo geral, pode-se concluir que as professoras e tutoras são mais cobradas no desempenho de suas funções por consequência da avaliação da Escola Nota 10. Enquanto os oficineiros são cobrados para mostrar o que está sendo desenvolvido nas oficinas, nos eventos da escola e no desfile cívico realizado anualmente.

A utilização da ampliação da jornada escolar para "reforço", visando o alcance de resultados, é tão intensa que as tutoras da Escola Municipal TEI são orientadas pelo Coordenador da Tutoria e do Programa Ciranda Curricular a manter as crianças em sala e desenvolver atividades de reforço escolar nas disciplinas de português e matemática. Mesmo as crianças passando o dia na escola e a maior parte do tempo dentro de sala de aula, as tutoras não podem desenvolver atividades nas áreas externas da escola. As crianças só podem sair da sala quando 
vão para as oficinas. No dia que não tem oficina, tem que permanecer na classe.

Esse aspecto de manter as crianças o tempo inteiro em sala é bem controverso com a proposta educacional de educação integral e escola de tempo integral, tendo em vista que se propõe o aumento de horas na escola para propiciar aprendizagens significativas que contribuam para a formação do ser humano em suas múltiplas dimensões (MACHADO, 2012). Tal fato também se contrapõe a muitas experiências históricas que influenciaram a motivação para implantar as escolas de tempo integral, como é o caso do Movimento das Cidades Educadoras e do Programa Mais Educação, que serviram de ações indutoras para se pensar as escolas em tempo integral.

Tanto o Movimento das Cidades Educadoras quanto o Programa Mais Educação orientam a prática de atividades intersetoriais promovidas pela ação conjunta das políticas públicas para se constituir redes educativas, explorando os espaços disponíveis no entorno da escola e na cidade na qual os educandos estão inseridos, para significar a aprendizagem e o conhecimento adquirido. Titton e Pacheco (2012) afirmam que é um desafio histórico repensar e superar as práticas tradicionais que centram a educação escolar nas salas de aula, com o ensino fragmentado do conhecimento. Para essas autoras, "O paradigma da educação integral que ora se estabelece agrega outros princípios nessa direção: a territorialização, a intersetorialidade e os arranjos educativos representam avanços para a superação desse desafio" (TITTON; PACHECO, 2012, p. 150).

Mesmo diante da concepção de educação integral, que muitas vezes traz à tona a escola como um espaço para o desenvolvimento da própria unidade escolar, as ações educativas escolares ainda estão centralizadas no espaço da escola. Não está se defendendo aqui que as ações educativas aconteçam exclusivamente fora das salas de aula ou da escola, mas se pretende esclarecer que a atitude de manter as crianças dentro da sala de aula durante o dia inteiro, todos os dias da semana, não condiz com a proposta de educação integral, nem com as experiências educativas de escolas de tempo integral que existiram no país.

Esse fato que acontece na Escola Municipal TEI remete ao entendimento que Arroyo (1988) expõe quanto a uma perspectiva da escola em tempo integral que carrega esse aspecto do controle social das classes menos favorecidas da sociedade. Segundo ele,

Não se amplia o tempo para poder ensinar e aprender mais e melhor, mas para poder experimentar relações e situações mais abrangentes: alimentar-se, assear-se, brincar, relacionar-se, trabalhar, produzir coletivamente na escola. Acredita-se na força educativa de experimentar vivenciar uma ordem, uma organização social o mais total possível. (ARROYO, 1988, p. 4).

Essa regra de manter os educandos sempre em sala suscita certa indisciplina nas crianças. Em muitos momentos foi possível observar as crianças brincando em sala, muitas circulam pelos corredores da escola até que os inspetores as conduzam novamente para sala e/ou, dependendo da situação, sejam encaminhadas para a sala dos especialistas e diretoria. Percebe-se que o momento mais esperado é o horário do recreio, no qual eles podem extravasar suas energias. Tal indisciplina se intensifica mais no período da tarde. A Tutora do $5^{\circ}$ ano B menciona essa questão:

Porque durante a manhã, as crianças, elas estão calmas, porque acordaram, o sono tá ainda, né?! E à tarde não, elas já estão saturadas de uma manhã cansativa, né?!, à tarde também. Então, é mais trabalho e você vai tá com a turma agitada, uma turma que não vai ser... que não vai ter... aquela concentração. (TUTORA DO $5^{\circ}$ ANO B).

Esse contexto remete ao entendimento de que a ação que vem sendo desenvolvida na Escola $\mathrm{Mu}-$ nicipal TEI acarreta o disciplinamento dos corpos infantis, legitimados nos discursos de ordem, de obediência, de disciplina (PROBST; KRAEMER, 2012). Ainda nessa direção, Strazzacappa (2001, p. 69-70) explica que

Embora conscientes de que o corpo é o veículo através do qual o indivíduo se expressa, o movimento corporal humano acaba ficando, dentro da escola, restrito a momentos precisos como as aulas de educação física e o horário do recreio. Nas demais atividades em sala, a criança deve permanecer sentada em sua cadeira, em silêncio e olhando para a frente.

Parafraseando Arroyo (2012), para conseguir desenvolver uma educação integral em escolas de tempo integral se faz necessário superar o reducio- 
nismo do trabalho docente enclausurado na sala de aula, deixando de ver os educandos como mentes, pensamento e saberes incorpóreos. Isto porque "somos mentes de sujeitos corpóreos, temporais-espaciais, de vida, não mentes, vontades abstratas incorpóreas aespaciais, atemporais que pouco temos relacionado as possibilidades de aprender com as possibilidades de viver" (ARROYO, 2012, p. 42). Assim, para garantir o direito da integralidade das vivências dos corpos é preciso priorizar outros espaços diferentes da sala de aula, diversificar os espaços, as atividades e os recursos (ARROYO, 2012). Nesse sentido, está posta a disputa entre a perspectiva do "integralidade do sujeito" e cobrança dos resultados, sendo esta última a dominante.

\section{Considerações Finais}

Ao efetivar a proposta metodológica desse estudo, encontrou-se como principais resultados que a implantação das escolas de tempo integral no Brasil não optou pelo modelo universal, como ocorreu em outros países. O modelo adotado em João Pessoa está centrado na ampliação do tempo, na perspectiva do aluno em tempo integral (CAVALIERE, 2009), assim como a política do Projeto em tela foi pensada com visíveis influências do Programa Mais Educação e para atender à melhoria nos resultados das avaliações.

No processo de implantação do tempo integral não houve resistência por parte dos sujeitos que compõem a comunidade escolar, tendo em vista a maneira como a situação foi conduzida. Ocorreu um planejamento precedente da Secretaria Municipal para a inauguração do Projeto, de modo que a comunidade foi previamente preparada para a aceitação da mudança.

Contudo, não houve a produção de textos que sistematizassem as concepções, intenções, objetivos e operacionalização da ampliação do tempo. Quatro anos depois foi que o Plano Municipal de Educação trouxe informações referentes a tal política, entretanto, ainda havia lacunas no tocante a descrição dos perfis e atribuições dos profissionais que atuam na efetivação da política no contexto escolar. Tal descrição só apareceu no ano de 2018 , com o lançamento da Diretriz Normativa que orienta o trabalho nas escolas de tempo integral.
O Projeto possui uma boa infraestrutura, que coloca a Escola Municipal TEI em um padrão diferenciado da realidade da maioria as escolas públicas brasileiras, contudo há limitações, principalmente no que diz respeito à manutenção dos espaços.

Embora o Plano Municipal de Educação expresse a intenção de proporcionar uma formação diversificada com a oferta de oficinas, não foi identificada a presença de concepções de educação integral que fundamentam o Projeto Escola de Tempo Integral.

Ainda que a política do referido Projeto objetive o atendimento ao aluno em tempo integral, na prática a extensão da carga horária está atrelada à proteção social, servindo para reforçar o estudo dos conteúdos curriculares de português e matemática, visando elevar as médias nas referidas disciplinas, bem como obter bom desempenho nas avaliações externas e no Programa Escola Nota 10. Nesse ínterim, a ausência de concepções de educação integral que justifique o aumento da carga horária torna a permanência das crianças por dez horas na escola uma prática de ofertar mais do mesmo (ARROYO, 2012).

A ampliação do tempo, nessa realidade, visa primordialmente o desenvolvimento do reforço escolar como mecanismo de compensação e elevação de médias em avaliações quantificáveis (ARROYO, 2012), ainda que ofereça oficinas com propostas culturais, desportivas e tecnológicas. O tempo integral seria mais significativo se o trabalho realizado objetivasse e impulsionasse o desenvolvimento do sujeito como um todo, seu corpo em espaços-tempos humanos, relacionando as possibilidades de aprender com as possibilidades de viver (ARROYO, 2012).

No tocante ao trabalho docente, as mudanças educacionais trazidas pelas reformas dos anos 1990, que resultaram em transformações nas formas de gestão e organização do trabalho na escola, ampliaram o raio de atuação docente, responsabilizando os professores pelo êxito e fracasso dos programas (OLIVEIRA, 2004). Esses aspectos apresentam-se bem evidentes no Projeto Escola de Tempo Integral, no qual os profissionais se autorresponsabilizam e são cobrados para atingir a meta prevista para receber a premiação do Programa Escola Nota 10, corroborando com o que Ball (2006) 
expõe sobre performatividade. Nesse contexto, a "autonomia docente" é balizada pelo Programa Es- cola Nota 10 tornando a ampliação jornada escolar subordinada ao discurso dos resultados.

\section{REFERÊNCIAS}

ANDRÉ, Marli. O que é um estudo de caso qualitativo em educacão? Revista da FAEEBA - Educação e Contemporaneidade, Salvador, v. 22, n. 40, p. 95-103, jul./dez. 2013.

ARROYO, Miguel Gonzales. O direito ao tempo da escola. Cadernos de Pesquisa, São Paulo, n. 65, p. 3-10, maio 1988.

. O direito a tempos - espaços de um justo e digno viver. In: MOLL, J. Caminhos da educação integral: direito a outros tempos e espaços educativos. Porto Alegre: Penso, 2012. p. 33-45.

BALL, S. J. Diretrizes políticas globais e relações políticas locais em educação. Currículo sem Fronteiras, v. 1, n. 2, p. 99-116, jul./dez. 2001.

Reformar escolas/reformar professores e os terrores da performatividade. Revista Portuguesa de Educação, Coimbra, Portugal, v. 15, n. 2, p. 3-23, 2002.

. Profissionalismo, gerencialismo e performatividade. Cadernos de Pesquisa, São Paulo, v. 35, n. 126, p. 539-564, dez. 2005.

. Sociologia das políticas educacionais e pesquisa críticosocial: uma revisão pessoal das políticas educacionais e da pesquisa em política educacional. Currículo sem Fronteiras, v. 6, n. 2, p. 10-32, jul./dez. 2006.

BONAMINO, A; FRANCO, C. Avaliação e política educacional: o processo de institucionalização do SAEB. Cadernos de Pesquisa, São Paulo, n. 108, p. 101-132, nov. 1999. Disponível em: <http://www.scielo.br/scielo. php?script=sci_arttext\&pid=S0100-15741999000300005\&lng=pt\&nrm=iso $>$. Acesso em: 07 jan. 2010.

BRASIL. Portaria Normativa Interministerial no 17, 24 de abril de 2007. Institui o Programa Mais Educação, que visa fomentar a educação integral de crianças, adolescentes e jovens, por meio do apoio a atividades sócio-educativas no contraturno escolar. Diário Oficial da União, Poder Executivo, Brasília, DF, 26 abr. 2007. Seção 1, p. 5.

. Presidência da República. Casa Civil. Decreto n $\mathbf{7}^{\mathbf{7 . 0 8 3}}$, de 27 de janeiro de 2010. Dispõe sobre o Programa Mais Educação. Brasília, DF, 2010. Disponível em: <http://www.planalto.gov.br/ccivil_03/_ato2007-2010/2010/ decreto/d7083.htm>. Acesso em: 09 mar. 2017.

. Ministério da Educação. Secretaria de Educação Básica. Manual Operacional de Educação Integral. Brasília, DF, 2012. Disponível em: <http://portal.mec.gov.br/index.php?option=com_docman\&view=download\&alias=11452-manual-operacional-de-educacao-integral-2012-pdf\&category_slug=agosto-2012-pdf\&Itemid=30192>. Acesso em: 13 ago. 2018.

Presidência da República. Casa Civil. Lei no 13.005, de 25 de junho de 2014. Aprova o Plano Nacional de Educação e dá outras providências. Brasília, DF, 2014. Disponível em: <http://www.planalto.gov.br/CCIVIL_03/_ Ato2011-2014/2014/Lei/L13005.htm>. Acesso em: 20 set. 2016.

Ministério da Educação. Saiba mais - Programa Mais Educação. Brasília, DF, 2016. Disponível em: $\overline{<h t t p: / / p o r t a l . m e c . g o v . b r / P r o g r a m a-m a i s-e d u c a c a o / a p r e s e n t a c a o ? i d=16689>. ~ A c e s s o ~ e m: ~} 05$ ago. 2016.

Censo Escolar da Educação Básica 2016: notas estatísticas. Brasília, DF: Instituto Nacional de Estudos e Pesquisas Educacionais Anísio Teixeira (INEP), 2017.

CASASSUS, Juan. A reforma educacional na América Latina no contexto de globalização. Cadernos de Pesquisa, n. 114, p. 7-28, nov. 2001.

CAVAliERE, A. M. Escolas de tempo integral versus alunos. Em Aberto, Brasília, DF, v. 22, n. 80, p. 51-63, abr. 2009.

ESTEVE, J. M. Mudanças sociais e função docente. In: NÓVOA, A. Profissão professor. Porto: Porto Editora, 2014. p. 93-124.

FANFANI, Emilio Tenti (Coord.). Estado del arte: escolaridad primaria y jornada escolar en el contexto internacional. Estudio de casos en Europa y América Latina. Buenos Aires: Secretaría de Educación Pública de México/ 
UNESCO/IIPE, 2010.

FELDFEBER, Myriam. La jornada completa en la ciudad de Buenos Aires: un análisis de sus fundamentos históricos, debates actuales y nudos críticos a casi medio siglo de su implementación. Buenos Aires: Gobierno de la Ciudad Autónoma de Buenos Aires/Secretaría de Educación/Dirección de Investigación, 2003.

GOROSTIAGA, J. M.; VIEIRA, L. M. Tendências nacionais e subnacionais no governo escolar: Argentina e Brasil, 1990 a 2010. In: OLIVEIRA, D. A.; PINI, M. E.; FELDFEBER, M. Políticas educacionais e trabalho docente: perspectiva comparada. Belo Horizonte: Fino Traço, 2011. p. 63-90.

JESUS, A. C.; BORGES, W. S. A ampliação do tempo escolar nas escolas públicas. Itinerarius Reflectionis - Revista Eletrônica da Pós-Graduação em Educação da UFG, v. 12, n. 1, 2016.

JOÃO PESSOA. Câmara Municipal de João pessoa. Lei no 11.607, de 23 de dezembro de 2008. Institui o Programa Escola Nota 10 no âmbito do município de João Pessoa e dá outras providências. João Pessoa, 2008. Disponível em: $<\mathrm{http}: / / 177.200 .32 .195: 9673 / \mathrm{sapl} / \mathrm{sapl}$ documentos/norma_juridica/14180_texto_integral $>$.Acesso em: 20 set. 2016.

. Prefeitura Municipal de João Pessoa. Lei no 13.035, de 19 de junho de 2015. Dispõe sobre o Plano Municipal de Educação 2015-2025, e dá outras providências. João Pessoa, 2015a. Disponível em: < https://leismunicipais. com.br/plano-municipal-de-educacao-joao-pessoa-pb>. Acesso em: 20 set. 2016.

Conselho Municipal de Educação. Resolução CME n⿳0 008, de 07 de abril de 2015. Dispõe sobre as Di-

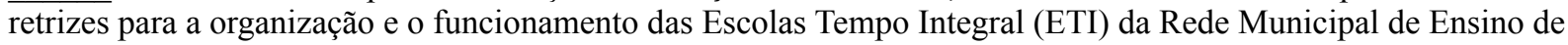
João Pessoa. João Pessoa, 2015b.

LESSARD, C.; TARDIF, M. As transformações atuais do ensino três cenários possíveis na evolução da profissão de professor? In:___ (Org.). O ofício de professor: histórias, perspectivas e desafios internacionais. Petórpolis, RJ: Vozes, 2008. p. 255-278.

LLORENS, Fernando R. Sobre la extensión de la jornada escolar en Uruguay: ocho supuestos de la política educativa en debate. Revista Latinoamericana de Estudios Educativos, Distrito Federal, México, v. XLIV, n. 2, p. 13-38, abr.jun. 2014.

MACHADO, A. S. Ampliação de tempo escolar e aprendizagens significativas: os diversos tempos de educação integral. In: MOLL, J. Caminhos da educação integral no Brasil: direitos a outros tempos e espaços educativos. Porto Alegre: Penso, 2012. p. 267-276.

MAINARDES, J. Abordagem do ciclo de poíticas: uma contribuição para a análise de políticas educacionais . Educação \& Sociedade, v. 27, n. 94, p. 47-69, jan./abr. 2006.

MARTINIC, Sergio. El tiempo y el aprendizaje escolar la experiencia de la extensión de la jornada escolar en Chile. Revista Brasileira de Educação, v. 20, n. 61, p. 479-499, abr./jun. 2015.

MOLL, J. A agenda da educação integral: Compromissos para sua consolidação como política pública. In:

Camihos da educação integral o Brasil: direito a outros tempos e espaços educativos. Porto Alegre: Penso, 2012.

Educação integral e reivenção da escola: elementos para o debate a partir do programa Mais Educação. In: OLIVEIRA, D. A.; DUARTE, M. R. Convergências e tensões no campo da formação e do trabalho docente: avalição educacional. Belo Horizonte: Autêntica, 2010. p. 853-869.

MONTEIRO, A. M. Ciep - escola de formação. Em Aberto, Brasília, DF, v. 22, n. 80, p. 35-49, abr. 2009.

OLIVEIRA, Dalila Andrade. As políticas educacionais no governo Lula: rupturas e permanências. Revista Brasileira de Política e Administração da Educação - RBPAE, v. 25, n. 2, p. 197-209, maio/ago 2009.

A reestruturação do trabalho docente/; precarização e flexibilização. Educação \& Sociedade, Campinas, $\overline{\text { SP, v. } 25, ~ n . ~ 89, ~ p . ~ 1127-1144, ~ s e t . / d e z . ~} 2004$.

PREAL. El tiempo y el aprendizaje en América Latina. Formas \& Reformas de La Educacion: Séries Políticas, ano 4, n. 11, mar. 2002.

PROBST, M.; KRAEMER, C. Sentado e quieto: o lugar do corpo na escola. Atos de Pesquisa em Educação, Blumenau, SC, v. 7, n. 2, p. 507-519, maio/ago 2012.

RODRIGUES, C. M. L.; CASTRO, A. E. G.; CUNHA JÚNIOR, J. L. O Programa Mais Educação: pretextos, contextos e práticas discursivas no Nordeste. Educação em Revista, Marília, SP, v. 18, Edição Especial, p. 73-94, 2017. 
RODRIGUES, C. M. Et al. O Programa Mais Educação: entre concepções, textos e práticas. In: CASTRO, A. L. Et al. Educação em tempo integral: ampliação de tempos, espaços e horizontes. Recife: Editora da UFPE, 2018. p. $11-40$

SANTOS, S. M.; DUBOC, M. J. Profissionalidade: saberes e autonomia docente. Olhar de Professor, Ponta Grossa, PR, v. 7, n. 2, p. 105-124, 2004.

STRAZZACAPPA, M. A educação e a fábrica de corpos:a dança na escola. Cadernos Cedes, v. 21, n. 53, p. 6983, abr. 2001.

TELLO, C. Perspectivas discursivas sobre profissionalização docente na América Latina. In: OLIVEIRA, D.; PINI, D. M.; FELDFEBER, M. (Org.). Políticas educacionais e trabalho docente: perspectiva comparada. Belo Horizonte: Fino Traço, 2011. p. 147-170.

TITTON, M. B.; PACHECO, S. M. Educação integral: a construção de novas relações no cotidiano. In: MOLL, J. Caminhos da educação integral no Brasil: direito a outros tempos e espaços educativos. Porto Alegre: Penso, 2012. p. 118-128.

VELEDA, Cecília. Nuevos tiempos para la educación primaria: lecciones sobre la extensión de la jornada escolar. Buenos Aires: Fundación CIPPEC/Unicef Argentina, 2013.

Recebido em: 03/10/2018

Aprovado em: 03/11/2018 